\title{
A Revised Algorithm for Estimating Queuing Time in Sensor Data Processing with Multiple Resources for U-Services*
}

\author{
Kang, Kyung-Woo** $\cdot$ Kwon, Ohbyung*** \\ $<$ 목 차> \\ I. Introduction V. Conclusion \\ ПI. Related Work References \\ III. Waiting-Time with Multiple Resources <Abstract> \\ IV. Experiments
}

\section{I . Introduction}

One of the critical issues in ubiquitous computing services is scalability, because such services must be accessible to distributed heterogeneous sensors through sensory network and then process in a real time manner to provide users with unobtrusive and timely service. The scalability issue in ubiquitous computing services comes from three aspects: agile context data processing, wireless and remote data transmission and variety of data types. First, within the allowed elapsed time requested from the applications, the acquired data must be used for the response. Unless the response happens before the expected time of response, the value of context data will be dramatically declined. Second, remote context data transmission becomes more important as the ubiquitous service zone is physically or logically larger. The sensors are unlikely to be in a vicinity of computer resources to make use of the sensor data such as RFID based systems.

* This work was supported by a grant from the Kyung Hee University in 2011.

** Division of Information and Communication, Baekseok University, Chonan, kwkang@bu.ac.kr *** Corresponding author, College of Management, Kyung Hee University, Seoul, obkwon@khu.ac.kr 


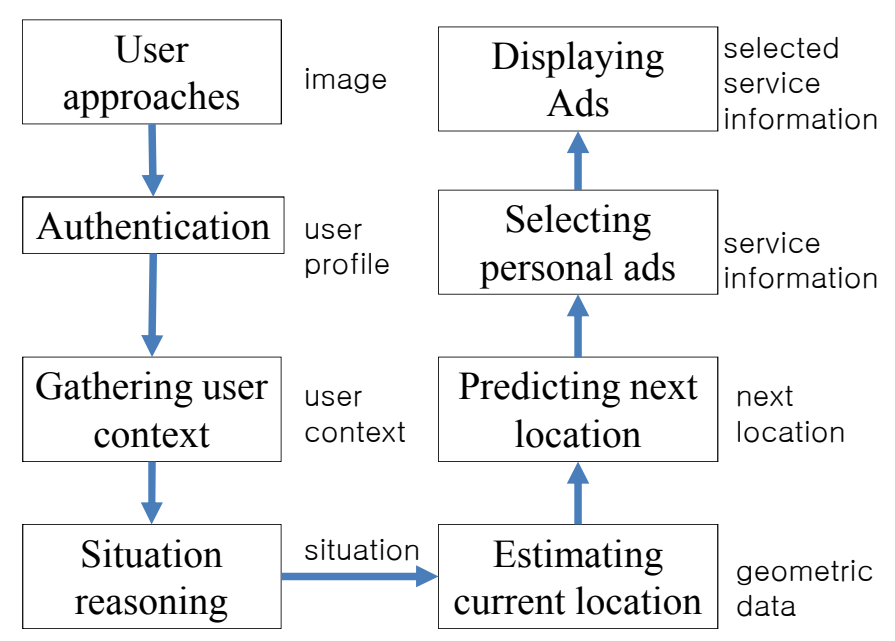

$<$ Fig. 1> Example of context-aware services

Quality of sensory systems influence the user acceptance (Kim et al., 2009; Kim, 2010). Last, the context data from sensors or any other personal resources may not be standardized in terms of data type and data amount to process at one time. The variety results in additional time and effort to reformatting or pre-processing source context data. The three aspects to characterize ubiquitous computing services are substantially related to scalability and system success.

Fig. 1 shows an example to demonstrate the characteristics of the real-time ubiquitous computing environment. Let's suppose that a shopping mall provides location-aware personal ads. A customer drives in parking lot of a shopping mall. After authentication and identifying personal resources such as user profile and context, situational data such as the purpose of visit or user's current needs are identified. The personal resources are useful to estimate the user's situation and select a context-aware service. Conventional location-based systems simply provide ads which already have been formatted and do not consider personalization. These potentially cause user dissatisfaction due to the customer's perception that he or she is disturbed by spam. To avoid this, various types of context data can be collected from the sensors and personal resource repository at the time of the event that the customer approaches to the shopping mall. Context data even can be combined or filtered if necessary. To provide the customer with ads just-in-time by a device which is currently available and usable in terms of vicinity, the customer's next location at the time when an ad is selected and delivered to the device. Moreover, ads provision method is also determined. The provisioning method can be 
visual, aural, olfactory or manual by the employees in vicinity. If the approaching customers are very crowded and just-in-time personal ads are needed, then some context data must be ignored to save time to situation reasoning and database query and personal ads generation. Displaying personal ads after the customer passes by is meaningless. Sometimes context data may be prioritized to manage the scalability. When this happens, prioritized context must be allocated to the computing resources by holding or ignoring context data of lower priority. For example, when a more valuable customer comes in, current processing for another customer may be halted or canceled.

The scenario shown in Fig. 1 implies that real-time ubiquitous computing services are characterized by real-time and timely processing. If the real-time and timely processing is not possible, then the sensor data must be abandoned. Or incoming prioritized sensor data affect the schedule of currently being processed and waiting tasks. To avoid or minimize the task cancelation and hence increasing scalability, the computing resources such as processing unit, memory and database must be supplemented. Moreover, the increase of computing resources must be optimized by considering economical constraint. Even though these problems are very important yet not simple, the effect of supplementing computing resources has not been clearly estimating in the current ubiquitous computing studies.
Hence, the purpose of this paper is to propose a method of resource assignment considering prioritization in real-time ubiquitous computing systems. Estimating the queuing time of current sensor data in case of allocating multiple computing resources to ubiquitous middleware is also proposed. By conducting some experiments, the relationship of the number of resources and queuing time is identified. We generalize the assumption of the earlier study which only assumed that only a single resource is available in each phase of context reasoning (Kang et al, 2011). Problem of assigning multiple finite resources to sensor data processing is considered because the nature of assignment method significantly affects queuing time.

The remaining part of this paper is organized as follows: In section 2, the conventional approaches to compute queuing time considering sensor data, processing time and queuing time are described. In Section 3, main idea of queuing time estimation method based on the availability of the multiple resources is proposed. Moreover, resource assignment methods for sensor data in queue are compared. Performance evaluation and the explanation of the results are shown in section 4. Lastly, section 5 concludes the contribution and further research issues. 


\section{Related Work}

In this section, conventional concept and notion of sensor data processing are described to define the computation of queuing time in the scope of real-time ubiquitous computing environment as in previous work (Kang et al., 2011). $\notin=<\mathrm{S}_{1}, \mathrm{~S}_{2}, \cdots, \mathrm{S}_{m}>$ is a list of sensor data by order of arrival time. Each set of sensor data arrives at the ubiquitous computing service through sensory network. $\operatorname{Succ}\left(\mathrm{S}_{i}\right)$ is a set of all sensor data which arrive right after $\mathrm{S}_{i}$ arrives. Likewise, $\operatorname{pred}\left(\mathrm{S}_{i}\right)$ can be defined as a set of all sensor data which arrive before $\mathrm{S}_{i}$ arrives. Therefore, $\operatorname{succ}\left(\mathrm{S}_{i}\right)$ and $\operatorname{pred}\left(\mathrm{S}_{i}\right)$ could be written as $\left\{\mathrm{S}_{i+1}, \mathrm{~S}_{i+2}, \cdots, \mathrm{S}_{m}\right\}$ and $\left\{\mathrm{S}_{1}, \mathrm{~S}_{2}\right.$, $\left.\cdots, \mathrm{S}_{i-1}\right\}$, respectively. It is assumed that a set of sensor data has lower priority than the former one and has higher priority than its successive one. It means that processing any sensor data could not be stopped for processing its successive one first. $\beta_{0}=<\mathrm{P}_{1}, \mathrm{P}_{2}, \cdots, \mathrm{P}_{n}>$ is a sequence of the phases that process sensor data. The number of phases and the kinds of phases vary depending on the nature of ubiquitous computing service. The arrival time of $\mathrm{S}_{i}$ is written as $\mathrm{a}_{i} \cdot \mathrm{t}_{i j}$ represents the time taken for a resource to process $\mathrm{S}_{i}$ at $\mathrm{P}_{j}$. Let us suppose there is a constraint that any phase is not able to process more than one sensor data simultaneously. If two sensor data should be processed at a phase simultaneously, then one of them has to wait until its former sensor data are processed completely. Hence, the waiting time and latency are important factors to measure the performance of real-time system (Bumbalek et al, 2010; Schurgers et al., 2002). Furthermore, the waiting time potentially causes service loss if the serviceable time is longer than the service request.

The processing time of each sensor data in each phase could be estimated with the quantity of data and forecasted loading. The data quantity can be regarded as the amount of data in queue, the transition of the amount and the slope of the transition. Even though the load of the ubiquitous middleware can be forecasted with several methods, the forecasting is beyond the scope of this paper.

The minimum time taken for $i$-th sensor data $\mathrm{S}_{i}$ to be processed from $\mathrm{P}_{1}$ to $\mathrm{P}_{k}$ can be defined as following;

$$
\mathrm{T}_{i}(k)=\sum_{1 \leq j \leq k} \mathrm{t}_{i j}+\mathrm{a}_{i}
$$

If $\mathrm{S}_{j} \in \operatorname{succ}\left(\mathrm{S}_{i}\right)$ is true, then the time for $\mathrm{S}_{j}$ should wait for $\mathrm{S}_{i}$ being processed at $k$-th phase $\mathrm{P}_{k}$ is represented as $\mathrm{T}_{i j}(k) . \mathrm{T}_{j}(0)$ is assumed to be 0 for the computation.

$$
\mathrm{T}_{i j}(k)=\mathrm{T}_{i}(k)-\mathrm{T}_{j}(k-1)
$$

When this formula are applied to whole phases, the waiting time when sensor data $\mathrm{S}_{j}$ should wait for its all former sensor data, can be taken as following;

$$
\mathrm{d}_{j}=\max _{1 \leq k \leq n} \mathrm{~T}_{i j}(k)
$$


_ A Revised Algorithm for Estimating Queuing Time in Sensor Data Processing with Multiple Resources for U-Services

where $\mathrm{d}_{j}$ indicates the waiting time of $j$-th sensor data under the condition that it is not allowed to pass its former sensor data. If the former sensor data should be processed on a phase but the sensor data does not have to be done on the same phase, it could be allowed to pass the former on that phase. This fact can be used for inducing some conditions. If $\left(\mathrm{t}_{j k}=\right.$ 0 and $\mathrm{T}_{i j}(k-1) \leq 0$ and $\mathrm{T}_{j i}(k+1) \leq 0$ for $1 \leq k \leq$ $n)$ is true, then $\mathrm{S}_{j} \in \operatorname{succ}\left(\mathrm{S}_{i}\right), \mathrm{S}_{j}$ could pass $\mathrm{S}_{i}$ at the phase $\mathrm{P}_{k}$. Likewise, if ( $\mathrm{t}_{i k}=0$ and $\mathrm{T}_{j i}(k-1)$ $\leq 0$ and $\mathrm{T}_{i j}(k+1) \leq 0$ for $\left.1 \leq k \leq n\right)$ is true, then $\mathrm{S}_{i} \in \operatorname{succ}\left(\mathrm{S}_{j}\right), \mathrm{S}_{i}$ could pass $\mathrm{S}_{j}$ at the phase $\mathrm{P}_{k}$. The waiting time $d_{j}$ can be rewritten using the following two conditions:

$$
\begin{aligned}
& \quad \mathrm{d}_{j}=\min \left(\left\{\delta \mid \mathrm{T}_{i j}(k)-\delta \leq 0 \text { or } \mathrm{T}_{j i}(k)+\delta\right.\right. \\
& \left.\leq 0 \text { for } 1 \leq k \leq n \text { where } \mathrm{t}_{i k} \neq 0, \mathrm{t}_{j k} \neq 0\right\}
\end{aligned}
$$

$\mathrm{T}_{i j}(k)$ and $\mathrm{d}_{j}$ is useful to compute the waiting time of a set of sensor data if the number of its former sensor data is greater than 1 . If there are some sensor data in the queue and some are under the process of ubiquitous middleware, the waiting time of a new arriving sensor data can be computed with the processing time of every former sensor data. By the waiting time, a list to be processed is generated from $\notin=$ $<\mathrm{S}_{1}, \mathrm{~S}_{2}, \cdots, \mathrm{S}_{m}>$. The ubiquitous computing middleware could process all sensor data of the processing list according to its order.

\section{Definition 1. Processing list}

Given an arrival list of sensor data, the waiting time of each sensor data could be computed. A processing list is generated from the waiting time of all sensor data. The processing list $<\mathrm{X}_{1}, \mathrm{X}_{2}, \cdots, \mathrm{X}_{m}>$ satisfies the following two conditions;

$$
\begin{aligned}
& \left\{\mathrm{S}_{1}, \mathrm{~S}_{2}, \cdots, \mathrm{S}_{m}\right\}=\left\{\mathrm{X}_{1}, \mathrm{X}_{2}, \cdots, \mathrm{X}_{m}\right\} \\
& \mathrm{a}_{i}+\mathrm{d}_{i} \leq \mathrm{a}_{j}+\mathrm{d}_{j} \text { for all } \mathrm{X}_{i}, \mathrm{X}_{j} \text { such that } i \leq j
\end{aligned}
$$

Algorithm 1 was proposed for the generation of the processing list (Kang et al., 2011). This scheme could be applied to the real-time ubiquitous computing environment when one resource is available for each phase.

Algorithm 1: Generation of the processing list for an arrival list

Input: An arrival list of sensor data, $\notin=<\mathrm{S}_{1}$, $\mathrm{S}_{2}, \cdots, \mathrm{S}_{m}>$

Output: A processing list of sensor data $\mathrm{L}$

$$
\begin{aligned}
& =<\mathrm{X}_{1}, \mathrm{X}_{2}, \cdots, \mathrm{X}_{m}> \\
& \mathrm{L}=<\mathrm{X}_{1}>\text { where } \mathrm{X}_{1}=\mathrm{S}_{1} \text { and } \mathrm{d}_{1}=0 \\
& \text { For } l=2 \text { to } m \\
& \text { Repeat } \\
& \text { For } i=1 \text { to } l-1 \\
& \text { If } \mathrm{d}_{i}+\mathrm{a}_{i} \leq \mathrm{d}_{l}+\mathrm{a}_{l} \text { Then } \\
& \mathrm{T}_{i}(k)=\sum_{1 \leq j \leq k} \mathrm{t}_{i j} \text { for } 1 \leq k \leq n \\
& \mathrm{~T}_{(}(k)=\sum_{1 \leq j \leq k} \mathrm{t}_{j j}+\left(\mathrm{d}_{l}+\mathrm{a}_{l}\right)-\left(\mathrm{d}_{i}+\mathrm{a}_{i}\right) \text { for } 1 \leq k \leq n \\
& \text { Else } \\
& \mathrm{T}_{i}(k)=\sum_{1 \leq j \leq k} \mathrm{t}_{i j}+\left(\mathrm{d}_{i}+\mathrm{a}_{i}\right)-\left(\mathrm{d}_{l}+\mathrm{a}_{l}\right) \text { for } \\
& 1 \leq k \leq \mathrm{n}
\end{aligned}
$$




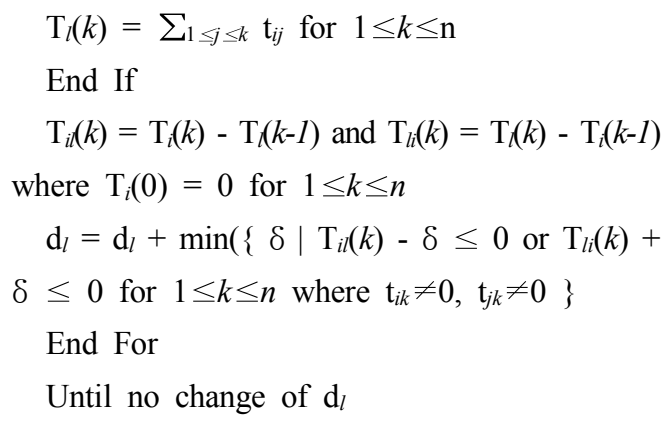

End For

\section{Waiting-Time with Multiple Resources}

In order to estimate the efficiency of ubiquitous computing middleware, we need to increase the number of resources for each processing phase. The increase could reduce the waiting time of a sensor data that is caused by its former sensor data. With infinite number of resources, the waiting time is always zero. The infinite increase of resources is far from practical for their great cost. Here, there is a trade-off between the performance of ubiquitous computing service and total cost for its resources. In the previous research, the waiting time was computed under the assumption that there is a single available resource for each phase.

In this section, we revised the algorithm for estimating queuing time in sensor data processing with multiple resources for u-services when the number of resources is extended to $\mathrm{r}_{k}$ for the phase $\mathrm{P}_{k}$. The resources are used to process all sensor data that arrive during the phase. The phase $\mathrm{P}_{k}$ could process $\mathrm{r}_{k}$ sensor data in parallel. If $m$ sensor data should be processed in the phase $\mathrm{P}_{k}$ where $m>\mathrm{r}_{k}$, some resources are required to process at least two sensor data. In this paper, we define a function $f_{i j}\left(\mathrm{P}_{k}\right)$ for indicating whether same resource should process two sensor data $\mathrm{S}_{i}, \mathrm{~S}_{j}$ at the phase $\mathrm{P}_{k}$. The value of $f_{i j}\left(\mathrm{P}_{k}\right)$ is logical; true or false. Truth means that same resource has to process both of them. However, they should be processed one by one at the resource. One of them should wait for the resource to finish processing the other at the phase $\mathrm{P}_{k}$ if $f_{i j}\left(\mathrm{P}_{k}\right)$ is true. If the value of $f_{i j}\left(\mathrm{P}_{k}\right)$ is false, they would be processed independently because their resources are different from each other.

If every phase could use multiple resources, the computation algorithm of waiting time is different from that of previous research. If two sensor data could be processed independently at same phase, a sensor data could be allowed to pass its former sensor data on that phase. This fact can induce some rules as following

\section{Rule 1. Sequential Processing Rule}

Condition: $\left(\mathrm{t}_{i k} \neq 0\right.$ and $\left.t j \neq 0\right)$ and $f_{\mathrm{ij}}\left(\mathrm{P}_{k}\right)=$ true and $\left(\mathrm{T}_{i j}(k)>0\right.$ and $\left.\mathrm{T}_{j i}(k)>0\right)$ for $1 \leq k \leq n$

- If $S_{i}$ is the former sensor data, $S_{j}$ should wait during $\mathrm{T}_{i j}(k)$. 
- If $\mathrm{S}_{j}$ is the former sensor data, $\mathrm{S}_{i}$ should wait during $\mathrm{T}_{j i}(k)$.

The condition means that two sensor data $\mathrm{S}_{i}$, $\mathrm{S}_{j}$ should be processed on the phase $\mathrm{P}_{k}$ and share same resource of the phase. In this circumstance, these sensor data should be processed sequentially. Among those, the former one is eligible to be processed prior to the other one and the successive one of them should wait for its former one if it does not have higher priority. The waiting time of the successive sensor data can be computed using rule 1 .

Rule 2. Passing Rule

Condition: $\left(\mathrm{t}_{i k} \neq 0\right.$ and $\left.t j k \neq 0\right)$ and $f_{\mathrm{ij}}\left(\mathrm{P}_{k}\right)=$ true and $\left(\mathrm{T}_{i j}(k)<0\right.$ or $\left.\mathrm{T}_{j i}(k)<0\right)$ for $1 \leq k \leq n$

- If $\mathrm{T}_{i j}(k) \leq 0$ and $\mathrm{S}_{i}$ is the former sensor data, $\mathrm{S}_{j}$ does not need to wait and could pass $\mathrm{S}_{i}$ at $k$-th phase $\mathrm{P}_{k}$.

- If $\mathrm{T}_{j i}(k) \leq 0$ and $\mathrm{S}_{j}$ is the former sensor data, $\mathrm{S}_{i}$ does not need to wait and could pass $\mathrm{S}_{j}$ at $k$-th phase $\mathrm{P}_{k}$.

The condition says that at $k$-th phase $\mathrm{P}_{k}$, two sensor data should be processed on same resource but at ( $k-1)$-th phase, the former one is processed and the successive one does not need to be processed at the same phase. Therefore the successive one is eligible to be processed at the $k$-th phase prior to the former one.

\section{Rule 3. Independent Processing Rule}

Condition: $\left(\mathrm{t}_{i k}=0\right.$ or $\left.\mathrm{t}_{j k}=0\right)$ or $f_{\mathrm{ij}}\left(\mathrm{P}_{k}\right)=$ false for $1 \leq k \leq n$

- One sensor data do not need to wait for the other one since they do not share the same resource with each other at $k$-th phase $\mathrm{P}_{k}$.

The partial condition $\left(\mathrm{t}_{i k}=0\right.$ or $\left.\mathrm{t}_{j k}=0\right)$ says that at least one sensor data do not need to be processed at the $k$-th phase. The rest condition $f_{\mathrm{ij}}\left(\mathrm{P}_{k}\right)=$ false means that two sensor data do not share the same resource at $k$-th phase $\mathrm{P}_{k}$. If one of the conditions is true two sensor data do not run into each other at the phase. Therefore two sensor data do not disturb each other.

The waiting time $d_{j}$ can be induced using Rule 1, Rule 2 and Rule 3 as following;

$$
\begin{array}{r}
\mathrm{d}_{j}=\min \left(\left\{\delta \mid \mathrm{T}_{i j}(k)-\delta \leq 0 \text { or } \mathrm{T}_{j i}(k)+\delta \leq 0\right.\right. \\
\text { for } \left.1 \leq k \leq n \text { where } \mathrm{t}_{i k} \neq 0, \mathrm{t}_{j k} \neq 0 \text { and } f_{\mathrm{ij}}\left(\mathrm{P}_{k}\right)=\text { true }\right\}
\end{array}
$$

$f_{\mathrm{ij}}\left(\mathrm{P}_{k}\right)$ is an important factor in computing the waiting time. If $m$ sensor data should be processed in $k$-th phase $\mathrm{P}_{k}$ where $m>\mathrm{r}_{k}$, some of them are required to share same resource. The waiting time could be affected by the methods that assign $r_{k}$ resources to $m$ sensor data. For the assignment, $\oplus_{k}=<\mathrm{X}_{1}, \cdots, \mathrm{X}_{l}>$ is defined as the list of sensor data whose processing time is not zero at $k$-th phase $\mathrm{P}_{k}$.

\section{(1) Sequential Assignment}

The available resources are allocated to every 
sensor data of the list $\mathbb{d}_{k}$ one by one regardless of the total processing time of each resource. This method makes every resource process subequal number of sensor data but have different total processing time. For example, let's assume that there are three available resources for $k$-th phase $\mathrm{P}_{k}$ and $\oplus_{k}=<\mathrm{S}_{1}, \mathrm{~S}_{2}$, $\mathrm{S}_{3}, \mathrm{~S}_{4}, \mathrm{~S}_{5}, \mathrm{~S}_{6}, \mathrm{~S}_{7}, \mathrm{~S}_{8}, \mathrm{~S}_{9}>$ is the list of sensor data that the phase $\mathrm{P}_{k}$ should process. If the available resources would be allocated sequentially, the list of sensor data are divided for the resources as following; $<\mathrm{S}_{1}, \mathrm{~S}_{4}, \mathrm{~S}_{7}>,<\mathrm{S}_{2}$, $\mathrm{S}_{5}, \mathrm{~S}_{8}>$ and $<\mathrm{S}_{3}, \mathrm{~S}_{6}, \mathrm{~S}_{9}>$ for three resources respectively.

Algorithm 2: Sequential Assignment of the Resources

Input: $\notin=<\mathrm{S}_{1}, \mathrm{~S}_{2}, \cdots, \mathrm{S}_{m}>$, the list of sensor data that arrive and queue.

Output: $f_{\mathrm{ij}}\left(\mathrm{P}_{k}\right)$ for $1 \leq \mathrm{i}, \mathrm{j} \leq m, 1 \leq k \leq$ $n$, after sequential assignment.

For $k=1$ to $n$ Let $\otimes_{k}=<>$

For $i=1$ to $m$

$$
\text { If } \mathrm{t}_{i k} \neq 0 \text { Then Let } \mathbb{e}_{k}=\mathbb{\leftrightarrow}_{k} \cdot<\mathrm{S}_{i}>
$$

End For

// Let's assume that $\left.\oplus_{k}=<\mathrm{X}_{1}, \cdots, \mathrm{X}_{l}\right\rangle$

For $i=1$ to $l$

Let $f_{\mathrm{ij}}\left(\mathrm{P}_{k}\right)=$ true such that $1 \leq \mathrm{j} \leq l$ and i Mod $\mathrm{r}_{k}=\mathrm{j}$ Mod $\mathrm{r}_{k}$

End For

End For

Such a sequential assignment might make the load of some resources much heavier than the others because the total processing time of resources is not considered. For example, if a list of sensor data $<\mathrm{S}_{1}, \mathrm{~S}_{4}, \mathrm{~S}_{7}>$ would be processed on the same resource at phase $\mathrm{P}_{k}, \mathrm{~d}_{4}$, $\mathrm{d}_{7}$ might be affected by $\mathrm{t}_{1 k}$. In order to overcome such a problem, a sensor data could be made for the resource that has lighter load. The load means the sum of the processing time of sensor data to be processed at the resource.

(2) Assignment of resources based on total processing time

This method considers total processing time of all sensor data which would be processed at the resource. When a set of sensor data arrives and queues, this method selects the resource whose total processing time is minimum for the sensor data. Let's illustrate this method with an example. Like the sequential assignment, our assumption is as follows; there are three available resources for $k$-th phase $\mathrm{P}_{k}$ and 9 sensor data on the queue $\left(\bigotimes_{k}=<\mathrm{S}_{1}, \mathrm{~S}_{2}, \mathrm{~S}_{3}, \mathrm{~S}_{4}, \mathrm{~S}_{5}, \mathrm{~S}_{6}, \mathrm{~S}_{7}, \mathrm{~S}_{8}, \mathrm{~S}_{9}>\right) . \mathrm{We}$ need one more assumption about processing time, so $<\mathrm{t}_{1 k}, \mathrm{t}_{2 k}, \mathrm{t}_{3 k}, \mathrm{t}_{4 k}, \mathrm{t}_{5 k}, \mathrm{t}_{6 k}, \mathrm{t}_{7 k}, \mathrm{t}_{8 k}, \mathrm{t}_{9 k}>$ $=<100,300,100,400,100,100,200,400$, $200>$ is assumed. The first resource is allocated to $\left\langle\mathrm{S}_{1}, \mathrm{~S}_{4}, \mathrm{~S}_{9}>\right.$, the second resource is allocated to $<\mathrm{S}_{2}, \mathrm{~S}_{7}>$ and the last resource would process $<\mathrm{S}_{3}, \mathrm{~S}_{5}, \mathrm{~S}_{6}, \mathrm{~S}_{8}>$.

Algorithm 3: First assignment of the resource 
with minimum total processing time

Input: The list of sensor data by arrival order $\left(\bigotimes=<\mathrm{S}_{1}, \mathrm{~S}_{2}, \cdots, \mathrm{S}_{m}>\right)$

Output: $f_{\mathrm{ij}}\left(\mathrm{P}_{k}\right)$ for $1 \leq \mathrm{i}, \mathrm{j} \leq m, 1 \leq k \leq n$

For $k=1$ to $n$ Let $\oplus_{k h}=<>$ for $1 \leq h \leq \mathrm{r}_{k}$

For $i=1$ to $m$

If $\mathrm{t}_{i k} \neq 0$ Then

Let $\otimes_{k h}=\otimes_{k h} \bullet\left\langle\mathrm{S}_{i}>\right.$ such that the processing time of $\Theta_{k h}$ is minimum

End For

For $h=1$ to $\mathrm{r}_{k}$

Let $f_{\mathrm{ij}}\left(\mathrm{P}_{k}\right)=$ true such that $\mathrm{S}_{\mathrm{i}}, \mathrm{S}_{\mathrm{j}} \in \mathbb{Q}_{k h}$

End For

End For

(3) Assignment of resources based on relations between sensor data.

This method uses the relations between two sensor data, which say if they could be processed independently. The relations could be defined between two sensor data as following.

\section{Definition 2.}

$\mathrm{S}_{1}<\mathrm{S}_{2}$ : If $\mathrm{S}_{1}, \mathrm{~S}_{2}$ are processed in order without any waiting time, $\mathrm{S}_{1}$ could proceed and finish on all phases before $\mathrm{S}_{2}$.

$\mathrm{S}_{1} \ll \mathrm{S}_{2}$ : If $\mathrm{S}_{1}, \mathrm{~S}_{2}$ start in order, $\mathrm{S}_{2}$ would pass it on some phases.

$S_{1} \| S_{2}$ : Without waiting time, they would meet at some phases and could not be processed in parallel.

This method divides the set $\&$ to several groups using the relations and assigns one resource to one group. If two sensor data $S_{1}$, $\mathrm{S}_{2}$ satisfy $\mathrm{S}_{1} \ll \mathrm{S}_{2}$ or $\mathrm{S}_{1} \diamond \mathrm{S}_{2}$, they could belong to same group because they could be processed in parallel. However, when $S_{1} \| S_{2}$ they'd better belong to different groups if possible. The computation of all relations is time-consuming job. For more efficient computation, we use one property that the relation $<<$ satisfies the property of transitive relation. That is, if $\mathrm{S}_{1}<<\mathrm{S}_{2}$ and $\mathrm{S}_{2}<<\mathrm{S}_{3}, \mathrm{~S}_{1}$ $<<S_{3}$ is true. This property make the inspection of $\mathrm{S}_{1}<<\mathrm{S}_{3}$ useless.

With one of three assignment methods, the queuing time of each sensor data could be computed for sensor data processing in real-time ubiquitous environment with multiple resources. Like Algorithm 1, Algorithm 4 can generate a processing list of sensor data for a given arrival list of sensor data. The processing list of Algorithm 4 has smaller total waiting time than the processing list of Algorithm 1.

Algorithm 4: Generation of a processing list of sensor data under a real-time ubiquitous environment with multiple resources

Input: An arrival list of sensor data $\notin=<\mathrm{S}_{1}, \mathrm{~S}_{2}$, $\cdots, \mathrm{S}_{m}>, f_{\mathrm{ij}}\left(\mathrm{P}_{k}\right)$ for $1 \leq \mathrm{i}, \mathrm{j} \leq m, 1 \leq k \leq n$

Output: A processing list of sensor data $\mathrm{L}$

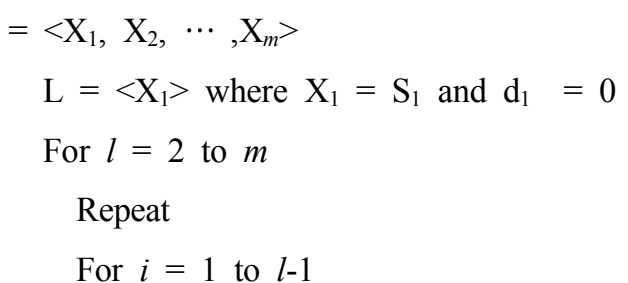




$$
\begin{aligned}
& \text { If } \mathrm{d}_{i}+\mathrm{a}_{i} \leq \mathrm{d}_{l}+\mathrm{a}_{l} \text { Then } \\
& \mathrm{T}_{i}(k)=\sum_{1 \leq j \leq k} \mathrm{t}_{i j} \text { for } 1 \leq k \leq n \\
& \mathrm{~T}_{l}(k)=\sum_{1 \leq j \leq k} \mathrm{t}_{i j}+\left(\mathrm{d}_{l}+\mathrm{a}_{l}\right)-\left(\mathrm{d}_{i}+\right.
\end{aligned}
$$

$\left.\mathrm{a}_{i}\right)$ for $1 \leq k \leq n$

Else

$$
\mathrm{T}_{i}(k)=\sum_{1 \leq j \leq k} \mathrm{t}_{i j}+\left(\mathrm{d}_{i}+\mathrm{a}_{i}\right)-\left(\mathrm{d}_{l}+\right.
$$

a) for $1 \leq k \leq \mathrm{n}$

$$
\mathrm{T}_{l}(k)=\sum_{1 \leq j \leq k} \mathrm{t}_{i j} \text { for } 1 \leq k \leq \mathrm{n}
$$

End If

$\mathrm{T}_{i l}(k)=\mathrm{T}_{i}(k)-\mathrm{T}_{l}(k-1)$ and $\mathrm{T}_{l i}(k)=\mathrm{T}_{l}(k)-$

$\mathrm{T}_{i}(k-1)$ where $\mathrm{T}_{i}(0)=0$ for $1 \leq k \leq n$

$\mathrm{d}_{l}=\mathrm{d}_{l}+\min \left(\left\{\delta \mid \mathrm{T}_{i l}(k)-\delta \leq 0\right.\right.$ or $\mathrm{T}_{l i}(k)$

$+\delta \leq 0$ for $1 \leq k \leq n$ where $\mathrm{t}_{i k} \neq 0, \mathrm{t}_{j k} \neq 0$ and $f_{\mathrm{ij}}\left(\mathrm{P}_{k}\right)=$ true $\}$

\section{End For}

Until no change of $\mathrm{d}_{l}$

Let $\mathrm{L}=<\mathrm{X}_{1}, \cdots, \mathrm{X}_{j-1}, \mathrm{~S}_{l}, \mathrm{X}_{j}, \cdots, \mathrm{X}_{i-1}>$ where $\mathrm{a}_{j-1}+\mathrm{d}_{j-1} \leq \mathrm{a}_{l}+\mathrm{d}_{l}$ and $\mathrm{a}_{l}+\mathrm{d}_{l} \leq \mathrm{a}_{j}+\mathrm{d}_{j}$

\section{End For}

Note that Algorithm 4 is different from Algorithm 1 only at line 13 . The waiting time $\mathrm{d}_{l}$ of a sensor data $\mathrm{S}_{l}$ could be influenced by the value $f_{\mathrm{ij}}\left(\mathrm{P}_{k}\right)$. The difference of the waiting time between two algorithms would be shown Section 4.

\section{Experiments}

For the experiments, we have implemented the algorithms described in Section 3 and compared the experimental results. In the first experiment, it is shown that the number of resources could affect the waiting time of successive sensor data. With the result of the experiment, we could estimate the decreasing rate of the waiting time according to the increase of resources. The second experiment tells the difference of three resource assignment methods. Method 1 allocates available resources to sensor data sequentially and method 2 does more intelligently using the information of load of resources. Method 3 makes the sets of sensor data using pattern relations and assigns one resource to one set. Table 1 shows the classification for experiments.

It is supposed that the expected processing time of every sensor data can be forecasted for this experiment. Table 2 shows 8 experimental sensor data with the expected processing time of each phase. The arrival time indicates the time when each sensor data begin to queue. The

$<$ Table 1> Classification for experiments

\begin{tabular}{|c||c|l|}
\hline & \multicolumn{1}{|c|}{ Comparison } & \multicolumn{1}{c|}{ Meaning } \\
\hline Experiment I & Algorithm 1 vs Algorithm 4 & $\begin{array}{l}\text { The affection rate of the increase of } \\
\text { resource to the waiting time }\end{array}$ \\
\hline Experiment II & Method 1 vs Method 2 vs Method 3 & $\begin{array}{l}\text { Method 3 could be used to process much } \\
\text { more sensor data }\end{array}$ \\
\hline
\end{tabular}


$<$ Table 2> Sensor data in the queue for experiment

\begin{tabular}{|c|c|c|c|c|c|c|c|}
\hline \multirow{2}{*}{ Data } & \multirow{2}{*}{$\begin{array}{c}\text { Arrival Time } \\
(\mathrm{ms})\end{array}$} & \multicolumn{6}{|c|}{ Expected Processing Time(ms) } \\
\cline { 3 - 8 } & & $\mathrm{P} 1$ & $\mathrm{P} 2$ & $\mathrm{P} 3$ & $\mathrm{P} 4$ & $\mathrm{P} 5$ & $\mathrm{P} 6$ \\
\hline $\mathrm{S}_{1}$ & 0 & 500 & 0 & 0 & 100 & 400 & 0 \\
\hline $\mathrm{S}_{2}$ & 0 & 0 & 300 & 100 & 100 & 0 & 100 \\
\hline $\mathrm{S}_{3}$ & 0 & 0 & 200 & 100 & 200 & 0 & 200 \\
\hline $\mathrm{S}_{4}$ & 0 & 0 & 0 & 300 & 100 & 100 & 0 \\
\hline $\mathrm{S}_{5}$ & 40 & 100 & 100 & 0 & 200 & 0 & 100 \\
\hline $\mathrm{S}_{6}$ & 50 & 0 & 100 & 200 & 0 & 300 & 100 \\
\hline $\mathrm{S}_{7}$ & 60 & 0 & 200 & 200 & 300 & 0 & 100 \\
\hline $\mathrm{S}_{8}$ & 70 & 100 & 0 & 200 & 0 & 300 & 100 \\
\hline
\end{tabular}

same data set is used for the experiment (Kang and Kwon, 2011).

Under the real-time ubiquitous environment where single resource is allocated to each phase, the queuing time of each sensor data is shown in Table 3 as an experimental result. The total waiting time of the table is the sum of waiting time of all sensor data and would be used for comparison.

Then an experiment is conducted to show how the waiting time is affected as the number of resources changes for all phases. In this experiment, it is assumed that every phase has the same number of resources. It is further research topic to differentiate the number of resources among each phase. The sequential assignment is used to distribute multiple resources to the sensor data on the queue. Table 4 shows that the waiting time of sensor data when multiple resources are sequentially allocated. The number of resources is changed from two to six. When the number is six and more, all sensor data can be processed independently.

When comparing the results in Table 3 with Table 4 , the total waiting time decreases greatly as the number of resources increases. The two times increase of resources makes the waiting time reduce less than half. However, from some sensor data's point of view, there are some cases that the waiting time is longer in spite of more resources. These cases occur when the list of sensor data of each resource varies. The change makes all resources have very different

$<$ Table 3> The waiting time of sensor data with single resource (ms)

\begin{tabular}{|c|c|c|c|c|c|c|c|c|}
\hline $\mathrm{S}_{1}$ & $\mathrm{~S}_{2}$ & $\mathrm{~S}_{3}$ & $\mathrm{~S}_{4}$ & $\mathrm{~S}_{5}$ & $\mathrm{~S}_{6}$ & $\mathrm{~S}_{7}$ & $\mathrm{~S}_{8}$ & Total waiting time \\
\hline 0 & 0 & 300 & 0 & 560 & 750 & 840 & 1130 & 3580 \\
\hline
\end{tabular}


$<$ Table $4>$ The waiting time of sensor data under method 1 (ms)

\begin{tabular}{|c|c|c|c|c|c|c|c|c|c|}
\hline $\begin{array}{c}\text { The number of } \\
\text { resources }\end{array}$ & $S_{1}$ & $S_{2}$ & $S_{3}$ & $S_{4}$ & $S_{5}$ & $S_{6}$ & $S_{7}$ & $S_{8}$ & Total waiting time \\
\hline 2 & 0 & 0 & 0 & 0 & 360 & 650 & 240 & 430 & 1680 \\
\hline 3 & 0 & 0 & 0 & 0 & 260 & 250 & 140 & 630 & 1280 \\
\hline 4 & 0 & 0 & 0 & 0 & 0 & 0 & 240 & 130 & 370 \\
\hline 5 & 0 & 0 & 0 & 0 & 0 & 0 & 140 & 230 & 370 \\
\hline 6 & 0 & 0 & 0 & 0 & 0 & 0 & 0 & 0 & 0 \\
\hline
\end{tabular}

processing time. If the processing time of a resource is substantially bigger, the sensor data to which the resource is allocated should wait for longer time. If the sensor data of big processing time converge on a resource, then it is no wonder that the waiting time of the sensor data becomes longer. This problem comes from the sequential assignment which does not consider the total processing time of each resource.

In order to solve that problem, in section 3, we described two assignment methods named method 2 and method 3. Method 2 is that the resource with minimum total processing time is given to a sensor data first. This method makes all resources subequal processing time. Table 5 shows the experimental result of that method.

If the result of Table 3 is compared with Table 5, it is found that the total waiting time decreases greatly as the number of resources increase like the comparison of Table 3 and Table 4. On the comparison of experimental results of Table 4 and Table 5, the total processing time of Table 5 is less than the time of Table 4. This result implies that if the resources would be allocated considering their total processing time, the total waiting time is less. Furthermore, as shown in Table 5, we could find more rarely the cases that the waiting

$<$ Table 5> The waiting time of sensor data under the assignment of the resource with minimum total processing time (ms)

\begin{tabular}{|c|c|c|c|c|c|c|c|c|c|}
\hline $\begin{array}{c}\text { The number of } \\
\text { resources }\end{array}$ & $\mathrm{S}_{1}$ & $\mathrm{~S}_{2}$ & $\mathrm{~S}_{3}$ & $\mathrm{~S}_{4}$ & $\mathrm{~S}_{5}$ & $\mathrm{~S}_{6}$ & $\mathrm{~S}_{7}$ & $\mathrm{~S}_{8}$ & Total processing time \\
\hline 2 & 0 & 0 & 0 & 0 & 260 & 350 & 440 & 630 & 1680 \\
\hline 3 & 0 & 0 & 0 & 0 & 160 & 250 & 240 & 430 & 1080 \\
\hline 4 & 0 & 0 & 0 & 0 & 0 & 0 & 180 & 130 & 310 \\
\hline 5 & 0 & 0 & 0 & 0 & 0 & 0 & 140 & 230 & 370 \\
\hline 6 & 0 & 0 & 0 & 0 & 0 & 0 & 0 & 0 & 0 \\
\hline
\end{tabular}


— A Revised Algorithm for Estimating Queuing Time in Sensor Data Processing with Multiple Resources for U-Services

$<$ Table 6> The waiting time of sensor data under the assignment of resources using relations between sensor data (ms)

\begin{tabular}{|c|c|c|c|c|c|c|c|c|c|}
\hline $\begin{array}{c}\text { The number of } \\
\text { resources }\end{array}$ & $\mathrm{S}_{1}$ & $\mathrm{~S}_{2}$ & $\mathrm{~S}_{3}$ & $\mathrm{~S}_{4}$ & $\mathrm{~S}_{5}$ & $\mathrm{~S}_{6}$ & $\mathrm{~S}_{7}$ & $\mathrm{~S}_{8}$ & Total processing time \\
\hline 2 & 0 & 0 & 0 & 0 & 360 & 250 & 140 & 530 & 1280 \\
\hline 3 & 0 & 0 & 0 & 0 & 0 & 150 & 180 & 370 & 700 \\
\hline 4 & 0 & 0 & 0 & 0 & 0 & 0 & 140 & 170 & 310 \\
\hline 5 & 0 & 0 & 0 & 0 & 0 & 0 & 0 & 0 & 0 \\
\hline
\end{tabular}

time is longer in spite of more available resources. From the some sensor data's point of view, it's waiting time decreases as the number of resources increases.

Method 3 for assigning resource is implemented and compared with the previous assignment methods. This assignment method uses three relations defined in section 3. The relations are useful for making the set of sensor data which would be processed on same resource.

Table 6 shows the waiting time of each sensor data when available resources are allocated to the groups made with the relations.
The waiting time of method 3 is smaller than that of method 2 because method 3 could use the information obtained through the relation analysis. However, it takes longer for method 3 to compute the waiting time because it should analyze the relation between every two sensor data. It may be a burden for real-time ubiquitous service.

In order to justify our assignment methods, we have conducted same experiments with large data. In this experiment, the number of sensor data increases from 100 to 500 by 100 for the total waiting time. The experimental result will show the difference among three

$<$ Table 7> Total waiting time according to resource assignment methods (ms)

\begin{tabular}{|c|c|c|c|c|c|c|}
\hline & \multicolumn{2}{|c|}{ Method 1 } & \multicolumn{2}{c|}{ Method 2 } & \multicolumn{2}{c|}{ Method 3 } \\
\hline $\begin{array}{c}\text { The number of } \\
\text { resources } \\
\text { of sensor data }\end{array}$ & $\begin{array}{c}1 / 4 \text { of the } \\
\text { number of } \\
\text { data }\end{array}$ & $\begin{array}{c}1 / 2 \text { of the } \\
\text { number of } \\
\text { data }\end{array}$ & $\begin{array}{c}1 / 4 \text { of the } \\
\text { number of } \\
\text { data }\end{array}$ & $\begin{array}{c}1 / 2 \text { of the } \\
\text { number of } \\
\text { data }\end{array}$ & $\begin{array}{c}1 / 4 \text { of the } \\
\text { number of } \\
\text { data }\end{array}$ & $\begin{array}{c}1 / 2 \text { of the } \\
\text { number of } \\
\text { data }\end{array}$ \\
\hline 100 & 62927 & 21516 & 54811 & 17663 & 50472 & 12842 \\
\hline 200 & 120985 & 48570 & 113065 & 43442 & 97695 & 31064 \\
\hline 300 & 185171 & 83497 & 181777 & 76263 & 160413 & 46872 \\
\hline 400 & 263913 & 123349 & 256085 & 113443 & 214223 & 79800 \\
\hline 500 & 312518 & 166849 & 319662 & 161286 & 266354 & 124750 \\
\hline
\end{tabular}


assignment methods. The number of available resources increases in proportion to the number of sensor data. We conducted two experiments for each assignment method; one case is that the number of resources is one-half of the number of sensor data and the other case is that the number of resources is a fourth of the number of sensor data.

The results of the experiments indicate that increasing the resources could reduce total waiting time to less, as expected. What we know from these experiments is that it provides significant improvement to increase the number of resources as many as possible.

\section{Conclusion}

Ubiquitous computing systems are requested to collect numerous sensor data called as context, generate higher level information from the sensor data, and respond adequately to the environment in a timely manner. Since the volume of sensor data is in general very huge due to the frequent sensing for providing better services, the imported sensor data are frequently stored in queue when the resources are busy in processing the former sensor data, rather than assigned to a computer resource instantly. Since the processing phases are independent of each other, resources other than being assigned can be available for the next sensor data. Former studies aimed to compute the queuing time for the next sensor data. However, they suffer from a drawback on the assumption that only one resource can process the sensor data at each phase, which is not free from the scalability concern. This lead those to assume a small scale ubiquitous space with moderate amount of sensor data to be processed, which no longer works in a real setting such as U-City services (Kim and Nam, 2010).

Hence, the proposed method can be applied to wider range of ubiquitous services which need real-time processing. In particular, real-time multiple agent scheduling problem can be coped with the proposed method (Garvey and Lesser, 1993). Second, our method has something to do with the agile service for the fast moving nomads or mobility-conscious scheduling problems. For example, context-aware tasks by the intelligent robots such as real-time sensor data processing or mobile RFID reader based moving object tracing, RTLS(Real Time Location System), and remote monitoring system can be benefited from the propose method (Nam et al., 2008).

When it comes to assigning resources to the incoming sensor data in a single phase, method 3 could decrease the queuing time more than sequential assignment (method 1) and simple load balancing method (method 2), which obviously shows that method 3 outperforms method 1 or 2. Method 1 (sequential assignment) was not more competitive especially when a larger volume of sensor data 
— A Revised Algorithm for Estimating Queuing Time in Sensor Data Processing with Multiple Resources for U-Services

are processed, the smaller but late arriving sensor data should wait in the queue. Moreover, we sometimes could find that the increasing queuing time in site of increasing the number of resources. This mainly comes from the case that larger volume of sensors data are assigned

Using the proposed method, we successfully demonstrated that we can estimate a packet of sensor data's queuing time when all multiple resources are assigned in a ubiquitous computing environment. We could observe that queuing time dramatically decreases by using multiple resources in processing former sensor data. However, increasing the number or capability of resources infinitely is not realistic due to financial limitations. Rather, we consider that the trade-offs between resource amount and queuing time. Accordingly, queuing time as performance is evaluated by varying the number of resources and resource assignment methods: First, only a single resource is considered, same as the previous study (Kang and Kwon, 2011), in calculating the queuing time of the sensor data in stack. Second, assuming the multiple resources, the processing priority is determined only by the coming event. Third, load balancing is considered to assign the multiple resources to the sensor data which are arrived in the resources at a different time. Last, the relations between sensor data is used for making sets of sensor data processed on same resource. As a result, when we increase the number of the resources, we could observe more than double performance. Increasing the resources gains more performance than expected.

In this paper, we assumed that the same amount of resources is assigned at each phase. This might not applicable to the realistic u-services simply because we have to allow a variety of devices. The number of resources and resource overload should be considered in the future. Also, it was supposed that the processing time of every sensor data can be forecasted. Scheduling with the stochastic processing time is another further research topic.

\section{References}

김상현, "RFID기술 수용과 구현에 영향을 주는 요인과 조직 준비성의 조절효과," 정보 시스템연구, 제19권, 제1호, 2010, pp.149-177.

김의창, 박명수, “시스템 상호 운용성을 위한 웹 서비스 기반의 RFID 미들웨어 구현," 정보시스템연구, 제18권, 제3호, 2009, pp.71-88.

김종기, 남수태, "U-City 분야별 서비스에 대한 선호도 분석," 정보시스템연구, 제9권, 제4호, 2010, pp.51-63.

Arasu, A., Babcock., B., Babu, S., Cieslewicz, J., Datar, M., Ito, K., Motwani, R., Srivastava, U., and Widom, J., STREAM: The Stanford Data Stream Management System. Technical Report. 
Stanford InfoLab, 2004.

Bumbalek, Z., Zelenka, J., and Kencl, L., "e-Scribe: Ubiquitous Real-Time Speech Transcription for the Hearing-Impaired," Proceedings of the ICCHP , 2010.

Galob, L., and Ozsu, M.T., "Issues in Data Stream Management," ACM SIGMOD Record, Vol.32, No.2, 2003, pp.5 14.

Garvey, A., and Lesser, V., "Design-to-Time Real-Time Scheduling," IEEE Transactions on Systems, Man and Cybernetics, Vol.23, No.6, 1993, pp.1491-1502.

Hastie, T., Tibshirani, R., and Friedman, J., "The Elements of Statistical Learning: Data Mining, Inference, and Prediction," Statistics in Medicine, Vol.23, No.3, 2004, pp.528-529.

Hatala, M., Wakkary, R., and Kalantari, L., "Rules and Ontologies in Support of Real-Time Ubiquitous Application," Journal of Web Semantics, Vol.3, No.1, 2005, pp.5-22.

Kang, K.W., and Kwon, O., "Queuing Time Computation Algorithm for Sensor Data Processing in Real-Time Ubiquitous Environment," Journal of Intelligence Information Research, Vol.17, No.1, 2011, pp.1-16.

Lee, B., Lim, S., and Kim, J., "Scalable Real-Time Monitoring System for Ubiquitous Smart Space," Information Processing Letters,
Vol.110, No.8-9, 2010, pp.294-299.

Liu, J. W. S., Real-Time Systems, Prentice Hall, 2000.

Musolesi, M., "Real-Time Ubiquitous Urban Sensing and Modelling," IEEE Internet Computing, Vol.12, No.4, 2008, pp. 12-21.

Nam, M., Al-Sabbagh, M. Z., Kim, J., Yoon, M., Lee, C., and Ha, E. Y., "A Real-Time Ubiquitous System for Assisted Living: Combined Scheduling of Sensing and Communication for Real-Time Tracking," IEEE Transactions on Computers, Vol.57, No.6, 2008, pp.795-808.

Schurgers, C., Tsiatsis, V., Ganeriwal, S., and Srivastava, M., "Optimizing Sensor Networks in the Energy-LatencyDensity Design Space," IEEE Transaction on Mobile Computing, Vol.1, No.1, 2002, pp.70-80.

Sim, S., Carbonell-MArquez, J. F., Spencer Jr., B. F., and Jo, H., "Decentralized Random Decrement Technique for Efficient Data Aggregation and System Identification in Wireless Smart Sensor Networks," Probabilistic Engineering Mechanics, Vol.26, No.1, 2011, pp.81-91. 


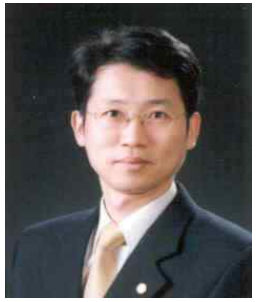

Kyung Woo Kang is presently an associate professor at Division of Information and Communication, Baekseok University, South Korea, where he initially joined in 2000 . He received the BS degree at Kyung Sung University in 1990, and MS and PhD degree in Computer Science at KAIST in 1992 and 1998, respectively. From 1998 to 2000, he worked for Super Computing Center at ETRI. In addition, he is now a visiting professor at Singapore Nanyang Technology University. His current research interests include Ubiquitous Computing, Grid Computing, and Compiler Theory.

권오병(Kwon , Ohbyung)

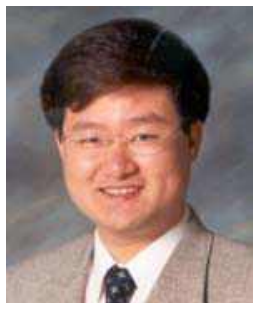

Ohbyung Kwon is presently a professor at Kyung Hee University, South Korea, where he initially joined in 2004. In addition, he is now working for Department of Information \& Decision Systems at San Diego State University as an adjunct professor. In 2002, he joined Institute of Software Research International (ISRI) at Carnegie Mellon University to perform myCampus project on semantic web and context-aware computing. He received the $\mathrm{MS}$ and $\mathrm{PhD}$ degree in Management Information System at KAIST (Korea Advanced Institute of Science and Technology) in 1990 and 1995, respectively. His current research interests include ubiquitous computing services, agent technology, mobile commerce, context-aware system development, case-based reasoning, and DSS. He has published various papers in leading information system journals such as Decision Support Systems. 
<초록>

\title{
유비쿼터스 서비스를 위한 복수의 자원을 가지는 센서 데이터 처리 대기시간 산출 수정 알고리즘 개발
}

\author{
강경우 · 권오병
}

실시간 유비쿼터스 환경의 규모성 향상을 위하여 각 처리 단계에 복수의 자원이 투입될 수 있다. 각 처리 단계에 복수의 자원이 배정되면 처리 단계 내에서 병렬로 처리되는 센서 데이터가 증가하기 때문에 후행 센서 데이터는 선행 센서 데이터의 처리 종료를 반드시 기다릴 필요가 없게 된다. 처리 과정이 서로 독립적인 센서 데이터들이 발생하면 후행 센서 데이터의 대기시간은 달라지게 된다. 본 연구에서는 복수의 자원이 사용 가능 할 때 후행 센서 데이터의 대기시간을 산출하는 알고리즘을 제안하였다. 또한 실험을 통하여 센서 데이터의 증가가 대기시간 감소에 얼마나 영향을 줄 수 있는지를 알아보았다. 실험을 통해 얻어진 결과는 자원이 개수를 2 배 증가시키면 대기시간의 감소는 2 배 이상이 라는 것이다. 복수의 자원을 각 처리 단계에서 센서데이터에 할당하는 방법에 따라 실험을 수행하였다. 첫 번째는 순차적으로 센서 데이터에게 자원을 할당하는 방법이고 두 번째는 자원이 처리해야 할 센서데이터 처리시간 합이 균등하도록 할당하는 방법이다. 두 가지 방법에 대한 실험으로 얻어진 결과는 자원을 할당함에 있어서 순차적으로 할당하는 것보다는 처리 시간 합이 균등하도록 자원을 할당하는 것이 대기시간 감소에 효과적이었다.

Keyword: 유비쿼터스 컴퓨팅 환경, 센서 데이터, 미들웨어, 실시간 시스템

* 이 논문은 2011년 9월 21일 접수되어 1차수정(2011년 11월 17일)과 2차수정(2011년 12월 6일)을 거 쳐 2011년 12월 22일 게재 확정되었습니다. 